\title{
Risk Control in Modeling Financial Management Systems of Large Corporations in the Digital Economy
}

\author{
Submitted 02/01/19, $1^{\text {st }}$ revision 06/03/19, $2^{\text {nd }}$ revision 18/04/19, accepted 25/05/19 \\ Vovchenko N.G. ${ }^{1}$, Andreeva O.V. ${ }^{2}$, Orobinsky A.S. ${ }^{3}$, Sichev R.A. $^{4}$
}

\begin{abstract}
:
Purpose: Growth in the uncertain business environment leads to the formation of demand for new institutional and legal conditions for the financial and investment strategies. The article discusses features of risk-oriented control in the context of digitalization.

Design/Methodology/Approach: The study involves modern concepts of uncertainty theory and risk management solutions coupled with the analysis of factors affecting the system risk formation and development.
\end{abstract}

Findings: Authors have developed the features of a modern global economic system, influencing risk formation and development, highlighted the prospects for the digitization of business systems and concluded that in terms of digitization interactive interagency cooperation of the real economy development support is main and required element of the Russian economic system's institutional matrix.

Practical Implications: The research results may be implemented into financial management systems of large industrial corporations.

Originality/Value: The main contribution of this study is the modern digitalization pattern affecting the financial systems ' development.

Keywords: Risk-oriented approach, system risk, financial management, industrial corporations, financial modeling, financial control, sustainable development.

JEL codes: G14, G17, G18, G27, H32.

Paper Type: Research article in Special Issue dedicated to Russian Economy. Section 1: Digital Economy.

\footnotetext{
${ }^{I}$ Professor, Vice Rector of Research and Innovation of the Federal State Budgetary

Educational Institution of Higher Education Rostov State University of Economics (RSUE), Rostov-on-Don, E-mail: nat.vovchenko@gmail.com

${ }^{2}$ Associate Professor of the Department of Economics and Finance, Rostov State Transport University, Rostov-on-Don, E-mail: a_o_v@mail.ru

${ }^{3}$ Associate Professor of the Department of Tax and Taxation Voronegh State Agricultural University named after Peter the First, Voronegh, E-mail: orobinski@mail.ru

${ }^{4} \mathrm{PhD}$ (Economics), Assistant Professor of the Department of Audit, Rostov State University of Economics, Rostov-on-Don, E-mail: Sichevroman@gmail.com
} 


\section{Introduction}

In contemporary reality, digital technologies, associated with financial controlling tools, are becoming an important condition for the economy's development and a factor in ensuring the industrial corporations' financial stability in the real economy. Russian economy continues to experience the effects of the global financial crisis and the imposed sectoral sanctions, resulting in a change in investors' expectations and correction in their investment strategies. Growth in the business environment uncertainty leads to the formation of an objective demand for new institutional and legal conditions for the financial and investment strategies implementation in a risky environment, and, naturally, for applied research in the development and testing of modernized forms of financial strategizing and financial control for corporate structures of the real economy, considering the need to solve the tasks of the Russian Federation strategic and socio-economic development.

\section{Materials and methods}

The research has a theoretical basis formed on the postulates of the quantitative school of management theory, institutional theory, systems theory, network economic theory, organizational management theory, economic philosophy school, financial globalization theory, modern concepts of uncertainty theory and risk management, digital economy concepts. In addition to general scientific methods, the research methodology includes system and diagnostic analysis in line with the system and functional approach, financial analytic methods, quantitative and qualitative risk assessment methods, risk-based approaches and group of graphical visualization methods.

\section{Results}

\subsection{Features of modern global economic system}

The "system risk" as an economic category started appearing in the analytical reports of relevant ministries of developed countries by leading analytical and consulting agencies (Thalassinos \& Thalassinos, 2018). The growth of the system risk, stochastic processes of its export and import as a part of the hyper-network form of the global economic system complicate achieving the goals of sustainable development. The features of modern global economic system expansion, influencing the system risk formation and development, are considered below.

First, an increasing level of financialization of all the areas of global economic system, combined with active development of digital, information and communication technologies should be highlighted. Total financialization of all areas of the global economic system, combined with active development of digital, information and communication technologies form a new type of economy. It is characterized by the factors and trends not considered in the economic fundamental 
concepts. At the same time, their influence on the value production remains indisputable. The absence of functional theoretical and methodological basis, describing and explaining accurately new factors and trends, has not been formed yet. At the same time, the contribution of virtual sector to the formation of cost and "value for the consumer" is obvious, but not in terms of reducing the cost of production against the background of increasing consumer value, but in terms of higher cost of high-tech components and increasing concentration in the high-tech market. At the same time, production of new value as a part of distributed international technological chains actualizes the problem of searching methods for evaluating the participation of virtual components in the value of not only real, but also of virtual products. In terms of this, an analysis of system risk in terms of new trends and tendencies of the global economy development is of particular interest in identifying priority areas of methodological, practical and applied research. Digitization of an already virtual financial sector leads to the withdrawal of global flows of financial resources from control and even from monitoring. Keeping track of implicit transnational financial flows is possible only with the help of comparative analysis, and with a low level of confidence.

Second, it should not go unmentioned, that dominant position of financial resources in relation to other production resources forms dependence of financial resources recipients on their suppliers (Rupeika-Apoga et al., 2018; Polyakova et al., 2019). It is financial determinism that has allowed introducing a sanctionable process into the category of non-economic, and at the same time, effective tools for the resource's redistribution in the global economy. Total dependence on the liquidity suppliers (from issuers to financial institutions) forces the leading players of the global market to consider geopolitical trends to the prejudice of classic business strategies. At the same time, financial parametric itself becomes more and more contradictory and dysfunctional: the government debt securities are equated to risk-free in the investment analysis, though, they are not, and never were, given at least the very existence of the estimated "country risk" parameter in the economic analysis. The countries leading in the concentration of financial capital (USA, Switzerland, etc.) are at the same time the poorest in terms of the public debt level per capita. Central banks, which, de-jure, are institutions obliged to implement a stable monetary policy, de-facto, underestimate credit risk, which leads to an unacceptable escalation of the risk burden in the financial and credit sector of specific countries and ensures fragility of the financial and credit mechanism. This, in its turn, changes in the financial and credit mechanism functionality from the "inter-sectoral flow of capital" to "ensuring the financial market operators' profitability", enhances development of financial speculation on the stock exchanges and forms a liquidity deficit in the real economy of the emerging countries. Thus, one of the most relevant issues of modern economic policy is to ensure a sustainable risk-oriented financial and credit mechanism, which is formed based on proactive digital technologies of analysis, forecasting and modeling. 
Third, growing uncertainty and the produced risks against the background of reducing investors' risk appetite limit investment activity in the real economy, resulting in the dominance of short speculative strategies. Russian small and medium-size business lowers its horizon of investment planning to short-term tactics (not more than $1-1.5$ years), while large projects in the real economy require a planning horizon of 3-5 years. Implementation of large projects in the real economy makes it necessary for co-investors to develop a financial mechanism for the risk hedging, which, on the one hand, increases investment attractiveness, and, on the other, withdraws financial capital from long-term investment projects in favor of short-term hedges. Because of these effects, economic turbulence grows stronger and becomes a self-reproducing and self-growing phenomenon, which cannot be leveled by market mechanisms (Albekov et al., 2017). To reduce the level of uncertainty in the economy, it is necessary to use new information and financial regulatory technologies, which include technologies of digitization, analytics and big-data, and a new model of financial controlling, based on them.

Fourth, uncertainty results in a continuous series of crises: socio-economic, financial, geopolitical, environmental, etc. These crises are becoming convergent: blurring the boundaries between crises and their integration leads to the effect of "continuity of crisis dynamics". At the same time, all the accumulated anti-crisis mechanisms known to the economics as branches of knowledge, in terms of network economics and turbulence, lose their effectiveness. Anti-crisis tools are becoming more customized and short-term. It should also be considered that anti-crisis strategies require significant resource support, which is not available to business entities. It simply has not been formed, since the reservation of resources contradicts to the spirit of total financialization, and the attracted resources require maintenance fees. This kind of risk-oriented reservation contradicts to the spirit of financial globalization and determinism, when all assets must work. At the same time, there is no development of the market infrastructure for allocating reserve funds in the financial market with the risk to return ratio acceptable for the owner.

Fifth, the risks of transfer of labor resources to virtual spheres, including the speculative investment spheres, should be mentioned. New phenomena of virtual economics (from SMM promotion to digital money (cryptocurrency)), robots and robotization, distributed registers (blockchain), quantum computers, big data, digital banking, 3D printing, and printed electronics) are highly profitable areas in terms of the economy digitization. This fact serves as an attractor for labor resources and human capital, causing them to transfer into the virtual economy sphere. In this case, an objective shortage of qualitative human capital in the real economy appears, where, in fact, the creation of value takes place. This naturally leads to the formation of two fractal groups of the economic growth organizational mechanism: one involves the atomization of society with its subsequent integration into production chains through information and communication administration (including the involvement of mass media technologies), the other involves "manual control" mode of development with administration by the bureaucratic nomenclature. Moreover, 
both types are destructive for production systems, since they are unable to ensure sustainable resource saving development.

Sixth, the growth in profitability of projects in the field of digitization leads to stochastic relocation of resources from the real economy to the digital sector (Andreeva et al., 2018). At the same time, there is an objective risk of the industrial base weakening and the digital superstructure hypertrophy. In several countries with a low economic potential more working-age people are employed in the field of cryptocurrency (mining and speculation) than in industry. At the same time, the robotized support of virtual exchanges reduces the level of requirements for the participants' competencies, thus excluding the self-employed population's motivation to obtain qualifications required in real economy, which, in its turn, will eventually create large imbalances in the labor market. Digital technologies are certainly able to provide an exponential growth of efficiency, but apart from the real cost production processes, they are non-productive and can only have a short-term speculative effect: algorithmicization and virtualization are useful only for ordered systems, otherwise it produces increasing chaos, stochastics and uncertainty.

Seventh, there is blurring in the control loops of the socio-economic systems development. Rhetoric of ensuring sustainable development, which has dominated among the social sciences for decades, has led to the adoption of several program documents for long-term development, which did not include new properties and characteristics of the changed global economy (Andreeva, 2016). The program documents are becoming less specific and contain less and less applied recommendations in terms of algorithms for achieving targeted states. On the one hand, this provides the possibility of maneuver in terms of rapidly changing business environment, and on the other, it produces regularly asynchronization between the economy's levels and sectors. The task of digitization is performed at an accelerating pace in the financial and credit sector, and much slower in the transport, construction, and agriculture sectors. This results unbalances in the control loops due to forced diversification of the strategic development management system in the part of tools, methods and algorithms, which, leads again to the manual control mode.

Eighth, risks of mismatch of monetary and industrial policy are increasing. In terms of post-crisis development in several countries, there was an imbalance in industrial and monetary policy in the part of the liquidity optimum in the market. Thus, Russian practice shows that banking institutions hold excess liquidity, while industry suffers from a shortage of available liquidity due to high interest rates (Andreeva and Shevchik, 2017). This leads to the lack of funding in working capital, which, in its turn, limits essentially the growth rate of industrial production and the possibility of the manufacturing infrastructure innovative modernization, as the demand capacity decreases in terms of available liquidity deficit, thus not allowing ensuring large modernization programs' implementation and the innovative developments' widespread introduction. 
Thus, the above factors and conditions for the system risk occurrence, though in very general terms, allow determining the features and contours of a new economic system, which, nevertheless, requires development and implementation of new algorithms for the economic growth activation. The economic growth activation is important not only as a part of the "new model of economic growth", but also as a part of existing models, since it is the efficiency of their implementation that creates the resource base for the possibility of renewal. It should be also noted that a modern economic system hyper-network organizational model does not allow taking seriously the rhetoric about the need for a production and socio-economic systems sharp and radical restructuring (e.g., as part of reengineering), since it is impossible to predict adequately the "long tails" of the consequences of managerial solutions in conditions of the hypernetwork. In modern conditions, it is advisable to move to a proactive management model, formed based on the risk-oriented system and diagnostic analytics using the tools of chaotic management (Glazyev, 2018), scenario approach, and modern content of the "continuous improvement concept" (TQM).

\subsection{Risks and prospects for the digitization of business systems}

High differentiation of countries and their macro regions in terms of their technical and technological development level raises rather sharply the issue of the role and place of digitization in the functioning of modern socio-economic systems, markets and business entities. "Fashionable" tendencies and trends dictated by digitization start turning digitization into a goal, leading the control loop from the content of the management process to its organizational characteristics. Certainly, the business processes algorithm development and their further digitization contribute to increased productivity; however, digitization itself cannot serve as a source of growth. Undoubtedly, digitization acts as a driver, improves communication efficiency, and can provide efficient use of resources. However, digital technologies introduced into economic circulation should be relevant to the business systems' goals and objectives. "Digitization for the sake of digitization" creates objective risks of management systems destabilization, which naturally leads to the control loop blurring and reduced potential for sustainable development.

It is difficult to overestimate the role and the place of human capital in modern economic systems. At the same time, the characteristics of the "human capital" definition have changed greatly. In core researches the expert community assigns more and more often a list of mandatory properties and characteristics to human capital, in fact, reflecting the ability of human capital to form flexible organizational groups (for example, adaptability, stress tolerance, innovative thinking and teamwork) that proves once again the uninterrupted connection between human and organizational capital. Capitalization of an intellectual product is impossible without a corresponding organizational circuit and a relevant amount of financial resources and applied financial technologies. 
The "economy of communications" demonstrates an equally important aspect of the digitization capabilities; it is the ability to organize communication platforms in digital environment. The ability to find and establish connections, make up long distributed chains of resources and participants, carry out the project promotion - all of this have passed from the know-how level into the segment of mandatory softskill for human capital (Klepach and Dobrocheev, 2015). In modern conditions, it is almost impossible to form a business project, and to ensure its implementation without these options. The investors' transition to short-term conservative strategies requires a more rapid deployment of business processes, which is possible only due to reducing operational and time costs using "digit".

In terms of the above, one of the most important tasks of the Russian higher education system is the training of personnel capable of ensuring the adaptation of the economic system to digitization. Among the graduates' competencies should be those that form their ability to perform labor functions for the replacement of routinized operations with robotics, the ability to ensure business processes continuity and to work in multitasking. Even though the robotization of routine operations is a very controversial trend in terms of social policy, the economic system should be ready for the phenomena characteristic of new technological structures. Glazyev (2018) aptly noted, one should focus not on reducing workplaces for workers of diffuse type, but on forming new ones intended for "neoanthropists", people capable of creative work during the time released by transferring routine operations to digital modules.

Thus, a conclusion can be made that the ratio of risks and expansion prospects of the digital economy is determined by the level of development of core competencies for the digital economy, which means that the focus is naturally shifted to the centers of competencies and their ability to ensure formation of the desired constructs of the human capital properties within research groups. In Russian practice, such institutions for the formation of competencies centers remain the higher educational institutions as areas of integration of academic science, practical and applied research with the involvement of specialized economic entities. Differentiation of the Russian Federation territory development levels is a significant driver for the development of digital competencies centers in order to adapt the digitization strategy to the territories' specificity and regional characteristics.

\subsection{Interactive interagency cooperation to support real economy}

In Russian practice, the real economy digitization concerns, first, engineering systems and logistics. Large investment in development of digital technologies of state and municipal administration had an effect. However, unfortunately, this effect can be considered as a positive experience only in the context of optimizing the interaction algorithms of private and public economy sectors on a very narrow list of issues: ensuring ergonomics of obtaining public services, as well as optimization of control and supervisory functions as a part of state, tax, and financial control. Such 
digital infrastructure, in our opinion, cannot be considered as a result sufficient to provide support for the development of large industrial corporations in the real economy. For example, the analysis of support programs for the agro-industrial enterprises showed (Osipov et al., 2018) that, despite wide graduation of tools, methods and forms of support offered to agricultural producers they all act separately, which does not give a synergistic effect in terms of growth points activation. This condition needs scientifically based development of an integrated model to support expansion of large industrial corporations of the real economy, including agro-industrial complexes.

Russian economic system digitization, on the one hand, allows ensuring acceleration of routine business operations. On the other hand, the metadata that are accumulated in existing information systems do not seem to receive proper analytical processing, which naturally leads to the fragmentation of support programs.

Thus, programs to support the agro-industrial enterprises' development do not offer effective specialized risk management tools produced by high volatility in foreign exchange markets. This contradicts the idea of import substitution and the task to develop export component of the Russian manufacturing industry. Absence of Russian electronic trading platforms able to compete with foreign exchanges to trade agricultural futures complicates significantly agro-industrial enterprises' financial strategies modeling. A priori sensitivity to negative impact of currency risks against the background of absence of effective tools for insurance risks of non-performance of contracts limits the opportunities of hedging. This naturally leads to the need to form funds, which, by their economic content, perform the functions of selfinsurance funds. At the same time, such a decision inevitably causes an increase in tax risks, since the Federal Tax Service of Russia naturally shows an interest in formally untargeted funding for agricultural enterprises.

It should be borne in mind that the current state of the global economic system and smart contracts' development determine the objective possibility of replacing elements of Russian administration systems with the opportunities offered by global information, trade, IT, cryptocurrency, and the "Internet of things". However, this creates an objective risk of cross-border management of significant processes in the national economic system of the Russian Federation. Therefore, the most urgent task, primarily in the context of national security, is the implication of advanced technologies in the support programs (Sychev, 2017). The priority task is to adapt real economy to new technological characteristics of new technological structures.

It is obvious that it is impossible to provide simultaneous reorganization of the real economy's entire infrastructure. However, it is quite possible to create the prerequisites for its transformation. In this context, it is required to use the opportunities provided by digitization. In addition, it should be considered right now that digitization changes the effect of the laws of value. If in traditional spheres the value of a product is directly determined by the amount of the used resources, than 
in the conditions of digital economy, on the contrary, the more data is accumulated and processed constructively, the cheaper production is, because in this context, the digitization reduces uncertainty (albeit locally, but reduces!). The evaluation of investment projects also changes due to localization and partial elimination of uncertainty: in digital economy, marginal investment efficiency increases in response to the expansion of business areas and coverage of new markets, rather than decreasing, as in the sphere of classical material production.

A review and analysis of business ratings applied in Russian practice demonstrates clearly that ranking and rating of the real economy enterprises is carried out primarily based on indicators from financial reporting forms, as well as on groups of indicators from fundamental financial analysis. At the same time, the level of financial potential that is different in economic content from the level of financial stability remains outside the research. Besides, agricultural producers' business reputation is out of focus too.

In our opinion, it seems reasonable to introduce analytical procedures into the system of preliminary selection of the agro-industrial companies to be included in state support programs. When consolidating the data of risk maps of financial potential heat maps (Figure 1) by industrial corporate structures, it is possible to form a more reliable idea not only of the integrated level of financial potential, but also of typical agro holdings' risks, which, in its turn, will allow developing more accurately an economic policy both at macro and mesoregion level.

Figure 1. Heat map of financial potential of companies belonging to an industrial corporation (extraction) (compiled by authors)

\begin{tabular}{|c|c|c|c|c|c|c|c|c|}
\hline Company & Block of financial indicators & 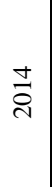 & $\frac{n}{\tilde{d}}$ & $\frac{0}{\stackrel{d}{d}}$ & 공 & $\frac{\infty}{\tilde{d}}$ & 胥 & 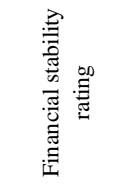 \\
\hline \multirow{5}{*}{ 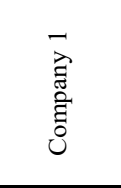 } & Liquidity management & 0,87 & 0,95 & 0,76 & 0,83 & 0,81 & $-0,024 \downarrow$ & \multirow{5}{*}{$53,0 \%$} \\
\hline & Accounts receivable and accounts payable mana & 0,75 & 0,86 & 0,52 & 0,45 & 0,58 & $-0,074 \downarrow$ & \\
\hline & Business management & 0,60 & 0,90 & 1,00 & 0,78 & 0,28 & $-0,077 \downarrow$ & \\
\hline & Financial independence & 0,66 & 0,87 & 0,54 & 0,68 & 0,50 & $-0,050 \downarrow$ & \\
\hline & Profitability and financial results & 0,49 & 0,82 & 0,26 & 0,37 & 0,30 & $-0,083 \downarrow$ & \\
\hline \multirow{5}{*}{ 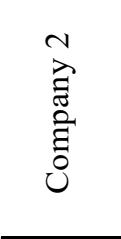 } & Liquidity management & 0,90 & 0,93 & 0,97 & 0,65 & 0,59 & $-0,089 \downarrow$ & \multirow{5}{*}{$57,0 \%$} \\
\hline & Accounts receivable and accounts payable mana & 0,48 & 0,35 & 0,61 & 0,62 & 0,67 & $0,066 \uparrow$ & \\
\hline & Business management & 0,80 & 0,69 & 0,57 & 0,05 & 0,18 & $-0,189 \downarrow \downarrow$ & \\
\hline & Financial independence & 0,87 & 0,84 & 0,91 & 0,36 & 0,71 & $-0,081 \downarrow$ & \\
\hline & Profitability and financial results & 0,84 & 0,97 & 0,99 & 0,13 & 0,66 & $-0,119 \downarrow$ & \\
\hline
\end{tabular}

Russian industrial corporations are far from being always reliably evaluated before they are included in state support programs. The facts of opportunism, low financial literacy of top management and high transaction costs of obtaining government 
support and reporting on its use lead to a lack of effectiveness of development programs. At the same time, world experience demonstrates the first and quite successful attempts at rating economic entities in terms of their integrity. Therefore, for example, in the PR China the system of citizens' rating by the level of conscientiousness and commitment is being successfully implemented, which allows motivating citizens to law-abiding and positive behavior, because high positions in the rating guarantee priority state support. Of course, this experience can be controversial in terms of constitutional rights and freedoms familiar to society, but it is interesting for the development of similar real sector's corporate structures rating.

Macro-regional aspects are key for the modernization and improvement of the institutional and legal infrastructure of the real Russian economy development support. Thus, the experience of a mega regulator's formation in the Russian financial market is a positive example of consolidating data on the status of financial market segments. Moreover, the experience of interactive non-contact interaction of the Federal Tax Service of Russia in analytics and tax administration demonstrates the effectiveness of contactless forms of interaction in the implementation of financial policy elements. In our opinion, it seems promising to develop a similar information system integrating information from the Russian Federation's Ministry of Agriculture, Federal Tax Service, and Ministry of Economic Development.

Interactive interagency cooperation will allow ensuring coordination of relevant ministries in terms of elaborating a balanced strategy for the Russian economy specific sectors development. An important fact is that it is interagency cooperation and integrated approach to analyzing risks and development opportunities for specific sectors of the Russian economy that will allow approximating solutions in the area of institutional and legal modeling to actual and relevant requests from the real economy representatives. For example, the problem of Russian electronic trading platforms formation and development of specialized insurance tools for the agro-industrial sector is an actual issue in modern conditions. However, it is precisely these areas that are not represented sufficiently in current economic policy tasks. This leads to the fact that even presence and active application of a riskoriented approach from the industry subjects comes across actual absence of accessible and effective financial risk management tools in the Russian financial market. The situation is complicated by uneven access of corporate structures to state support programs. In our opinion, the main task of real economy development support is a flexible and customizable institutional matrix of the Russian economic system, in which institutions are assigned areas of responsibility, and, together with them, obligation to provide the required functionality to the economic subsystems in the part of both financial tools and market infrastructure elements.

Thus, it can be concluded that in terms of digitization, interactive interagency cooperation of the real economy development support is a main and required element of the Russian economic system's institutional matrix, because balance of public and private sectors' interests, implementation of a risk-based approach and 
growth points' activation require regular and timely corrections in economic policy. Only integrated approach based on cross-platform interaction of various departments will allow not only identifying priority areas for management efforts, but also testing the adopted priority support models considering risk-oriented approach at macro level.

\section{Discussion}

\subsection{Digitization as the main driver for risk-based financial control systems}

In terms of growing uncertainty, accompanied by inevitable reallocation of financial resources, the problems of ensuring financial control effectiveness are becoming relevant. The use of digital technologies in state control is already widespread in Russian practice. Further development, in our opinion, should be carried out in direction of applying the blockchain technology, since it is this that cannot admit falsification of registration documents, falsification of permits, backdating of verification acts. Smart contracts provide transparency of procurement, and digital signatures technology further expand the potential of contactless forms of interaction.

In the area of corporate financial control, the use of digital technologies is limited by the level of digital infrastructure development and specialists' competence. Practice shows that increase in the volume of digital data and development of contactless forms of interaction do not always lead to a decrease in paperwork. This, in its turn, requires a hybridization of approach to control procedures, which, of course, reduces their efficiency. At the same time, general transition to a risk-based concept of financial management cannot stand delays and uncoordinated data, since this produces unreliability of the information and empirical basis for making managerial decisions. Risk maps and risk metrics (Tashtamirov et al., 2017) should be updated regularly, since it is based on their content that financial control selects priority areas for inspections and taking preventive measures. However, contradictions generated by different quality of information carriers, do not allow a smooth transition to a blockchain technology as a part of corporate financial control. Of course, distributed registry technologies have both advantages and disadvantages (Vovchenko et al., 2018), but in terms of digitization and increase in business operations speed, the effect of accelerated transfer of financial risks from meso and macro levels to micro level occurs. From a practical and applied point of view, this means challenge to a radical and accelerated transformation of internal financial control corporate systems.

The above internal financial control system should include modern monitoring and diagnostic systems, since conducting complete surveys without a risk-based approach in modern economy is no longer effective (Vovchenko et al., 2017). 
Monitoring systems should ensure tracking of key indicators for the real economy specific corporations, not only at meso and macro levels, but also at micro level. This will allow identifying short-term trends and differentiate them from long-term tendencies.

For example, the implementation of a functional settlement policy with contractors is not possible without analyzing and forecasting financial status of the counterparties in the industry and / or region. The level of counterparties' credit burden (creditors and debtors), combined with their tolerance to currency risks, largely determines their current solvency.

Thus, application of a risk-oriented approach in terms of digital economy cannot be limited only to the corporate level and ecosystem of the corporation. Modern conditions require enhanced analytical support for internal financial controlling procedures, since the areas where significant risks are produced in current conditions lie outside organizational contour of corporate structures, but they redefine the escalation vectors and directions of financial risk transmission.

\section{Conclusion}

Thus, a research of the risks relevant for global economy, integrally arising in the form of country risk, was conducted. An assessment of its dynamics was given. Directions of its impact on economic systems were determined. The risks and prospects for digital economy development were assessed. Therefore, the above allowed establishing a priority of human capital for the implementation of adaptive and proactive strategies at micro, meso and macro levels of the economy. The significance of the implementation of interactive interagency cooperation with the purpose to support the Russian real economy's development in terms of digitization was conditioned. Besides the role and place of risk-oriented control in modeling financial management systems of large industrial corporations in terms of digitization was shown. This allowed forming a conceptual approach to systemically important elements of the organizational, financial, institutional and legal infrastructures of the Russian economy.

\section{References:}

Albekov, A.U., Vovchenko, N.G., Andreeva, O.V., Sichev, R.A. 2017. Block Chain and Financial Controlling in the System of Technological Provision of Large Corporations Economic Security. European Research Studies Journal, 3B(20), 3-12.

Andreeva, L.Yu., Epifanova, T.V., Andreeva, O.V. Orobinsky, A.S. 2018. Competencybased management in a system of sustainable development of banks, financial and technology companies. Contemporary Issues in Business and Financial Management in Eastern Europe, 100, 49-60.

Andreeva, O.V. 2016. Investigation of the Genesis of Sustainable Development Definition Interpretations and Assessment of their Functionality for the Management Theory. State and Municipal Management. Scientific notes of the South Russian Institute of 
the Russian Presidential Academy of National Economy and Public Administration, 3, 55-63.

Andreeva, O.V., Shevchik, E.V. 2017. Organizational and Financial Modeling of Transnational Industrial Clusters Sustainable Development: Experience, Risks, Management Innovation. European Research Studies Journal, 1(20), 137-147.

Glazyev, S.Yu. 2018. Information and Digital Revolution. Eurasian Integration: Economics, Law, Politics, 1(23), 70-83.

Klepach, A.N., Dobrocheev, O.V. 2015. The Ensemble of Economic Waves or the Turbulent Hypothesis of the Economy. Philosophy of Economics, 6(102), 180-191.

Orobinsky, A.S. 2017. Financial Tools for Implementing the Policy of Import Substitution in the Agricultural Sector. Science and Education: Economy and Economics; Entrepreneurship; Law and Management, 1(80), 28-31.

Osipov, Yu.M., Yudina, T.N., Geliskhanov, I.Z. 2018. Digital Platform as an Institute for the Era of Technological Breakthrough. Economic Strategies, 5(155), 22-29.

Polyakova, A.G., Loginov, M.P., Serebrennikova, A.I. \& Thalassinos, E.I. 2019. Design of a socio-economic processes monitoring system based on network analysis and big data. International Journal of Economics \& Business Administration, 7(1), 130-139.

Rupeika-Apoga, R., Zaidi, H.S., Thalassinos, E.Y. \& Thalassinos, I.E. 2018. Bank Stability: The Case of Nordic and Non-Nordic Banks in Latvia. International Journal of Economics \& Business Administration, 6(2), 39-55.

Sychev, R.A. 2017. Development of a Financial Controlling System Based on Risk-Oriented Approach in Corporate Management. Science and Education: Economy and Economics; Entrepreneurship; Law and Management, 1(80), 24-27.

Tashtamirov, M.R., Tavbulatova, Z.K., Galazova, S.S., Abaev, R.M. 2017. Current Instability in the Monetary and Credit System of Russia. Journal of Applied Economic Sciences, 1(47), 303-311.

Thalassinos, I.E., Thalassinos, Y. 2018. Financial Crises and e-Commerce: How Are They Related. Available at SSRN: https://ssrn.com/abstract=3330169.

Vovchenko, N.G., Alukhanyan, A.A., Andreeva, L.Y., Buryakov. G.A. 2018. Formation of an Adaptive Personnel Training System as a Factor of Ensuring Financial Stability of Leasing Companies. European Research Studies Journal, S1(21), 3-15.

Vovchenko, N.G., Orobinskiy, A.S., Sichev, R.A., Holina, M.G. 2017. Ensuring financial stability of companies on the basis of international experience in construction of risks maps, internal control and audit. European Research Studies Journal, 20(1), 350-368. 